\title{
Cognitive Penetrability and Ethical Perception
}

In recent years there has been renewed philosophical interest in the thesis that perceptual experience ${ }^{1}$ is cognitively penetrable. ${ }^{2}$ Here is a characterisation of cognitive penetration and the cognitive penetrability thesis:

Cognitive Penetration: cognitive penetration is possible iff it is possible for two subjects to have experiences which differ in content and/or phenomenal character, where this difference is the result of a causal process that traces more or less directly to states in the subjects' cognitive system, and where we hold fixed the the perceptual stimuli, the condition of the subjects' sensory organs, the environmental conditions, and, the attentional focus of the subjects.

Cog-Pen Thesis: at least some experiences of human beings are cognitively penetrated.

Some clarification: in characterising cognitive penetration in terms of differences in content and character I am assuming a representational view of experience. According to this, experiences have contents which can be spelt out in terms of their accuracy conditions, and there is some important relation between content and phenomenal character, e.g., supervenience.

Cognitive penetration involves alterations in experience which are the result of causal influence from the subject's cognitive system. Two things to note: firstly, I am understanding 'cognitive system' broadly so as to include beliefs, desires, emotions, intuitions, concepts. Secondly, the causal impact that the cognitive system has in penetration should be distinguished from trivial cases where a subject's cognitive system causes them to have a different experience due to its bringing about changes in bodily position, e.g., my desire to see the bewildering

\footnotetext{
1 Hereafter I speak of 'experience' rather than 'perceptual experience'.

2 See, e.g., Lyons 2011, Macpherson 2012, Siegel 2012, 2013, Stokes 2012, forthcoming, Vance forthcoming.
} 
Suilven ${ }^{3}$ causes me to turn my body (and eyes) in its direction, thus having an experience of it. 4

The Cog-Pen Thesis is that cognitive penetration exists. Although the question of whether it does is by no means settled, there are many suggestive studies apparently supporting $\mathrm{it}^{5}$ and a priori arguments $^{6}$ in its favour. Hereafter I will assume that cognitive penetration is indeed a psychologically real occurrence. My focus will be on specific philosophical consequences that might follow.

As has been widely noted, it is plausible that cognitive penetration has implications for perception's epistemic role. On the one hand, penetration could make agents insensitive to the world in a way which epistemically 'downgrades' their experience. ${ }^{7}$ For example, if my expectational belief that 'bananas are yellow' comes to systematically bias my perceptual system towards representing bananas as yellow (even when the banana I'm confronted with isn't yellow), then this might reduce or eliminate the justification-conferring power of my experiences of the yellowness of bananas.

On the other hand, cognitive penetration could be epistemically beneficial by making agents more sensitive to the way the world is, i.e., by enabling them to see things that others cannot. For example, penetration could ground a 'highlevel' view of perceptual content, ${ }^{8}$ according to which agents can have

\footnotetext{
3 Suilven is a hill located in the spectacular Sutherland region of northwest Scotland.

4 Two further clarifications: firstly, the 'more or less directly' clause is to allow for cases where a cognitive state might influence perceptual experience indirectly. The sort of cases I have in mind are where a cognitive state causes the formation of some intermediary phenomenal state, or a non-cognitive state, which in turn affect the content and/or character of experience, e.g., my belief that the interview is tomorrow might cause me to have a migraine which in turn causes an experience of red flashing. It is of course a matter of controversy whether these cases count as cognitive penetration. Secondly, and relatedly, one might want to impose a semantic condition on cognitive penetration, such that there has to be some sort of logical or semantic coherence relation between the penetrator and penetrated states. See, e.g., Macpherson 2012, Pylyshyn 1999, and Stokes forthcoming for discussion.

5 See, e.g., Bruner and Goodman 1947, Delk and Filenbaum 1965, Hansen et al. 2006; Witzel et al 2011.

6 See Siegel 2006, 2007 for discussion of the method of phenomenal contrast.

7 See Siegel 2013 for discussion.

8 See, e.g., Bayne 2009, Siegel 2006
} 
experiences as of 'complex' properties, e.g., natural kind and aesthetic properties. Relatedly, it could elucidate the view that agents can gain perceptual expertise, e.g., ornithological, by learning.

A type of sophisticated perception (and associated 'perceptual expertise') which has hitherto received little attention in relation to cognitive penetration is ethical perception. This paper aims to fill this gap in the literature.

Although it is uncontroversial that perception can provide agents with non-ethical information which may partially ground ethical judgment, some ethical traditions appeal to a notion of 'ethical perception' which appears to go beyond this. Call these views 'Perceptualist'. Significant examples of Perceptualism can be found in the Virtue Ethics, Cornell Realist, and Ethical Intuitionist traditions. ${ }^{9}$ I will say more about these later. In the meantime, in order to get the flavour of Perceptualism, consider the following example:

Cat: If you round a corner and see a group of young hoodlums pour gasoline on a cat and ignite it, you do not need to conclude that what they are doing is wrong; you do not need to figure anything out; you can see that it is wrong. 10

Despite appealing to 'ethical perception' as part of their views, it isn't always clear how literally Perceptualists intend this. ${ }^{11}$ One way of sharpening loose talk of 'ethical perception', which has been the subject of much recent discussion, ${ }^{12}$ is the following view:

\footnotetext{
9 Another example can be found in Korsgaard's 1996 view that we cannot help seeing each other as ends. 10 From Harman, 1977, p. 4

11 e.g., Harman, who presents the Cat example, thinks that ethical observation is simply a psychologically immediate judgment on the basis of the way things look. See his 1977, p. 7.

12 See Cowan forthcoming a, forthcoming b, Cullison 2010, McBrayer 2010b, McGrath 2004, Vayrynen 2008.
} 
Ethical Perception: human agents can have perceptual experiences as of the instantiation of ethical properties, at least some of which are veridical. ${ }^{13}$

I will say more about this view and how it relates to varieties of Perceptualism shortly. For now let me bring this brief excursion into metaethics back to cognitive penetration. The idea to be considered is that cognitive penetration provides a way of grounding the truth of Ethical Perception, i.e., states in a subject's cognitive system could causally produce experiences with ethical contents. In doing so, cognitive penetration potentially has significance for Perceptualist views.

In this paper I examine the relationship between cognitive penetrability and three types of Perceptualism in ethics. The results are somewhat mixed: although cognitive penetrability does not support Perceptual Intuitionism, it may provide some limited support for Virtue Ethics and Cornell Realism. However, its significance should not be overstated.

After outlining the relation between Ethical Perception and brands of Perceptualism in detail in $\S 1$, in $\S 2$ I suggest that a cognitive penetration model is the most plausible account of Ethical Perception. In $\$ 3$ I argue that this model doesn't obviously constitute a theoretical advance for Virtue Ethicists. In §4 I discuss the epistemology of cognitively penetrated ethical experience, arguing that Cornell Realism is better supported by a cognitive penetration model than Perceptual Intuitionism. In $\S 5$ I conclude.

\section{Ethical Perception and Perceptualism}

In this section I clarify Ethical Perception and its motivations. This will involve a fuller discussion of forms of Perceptualism.

13 I follow recent discussions in assuming a representational view of perception and focusing on visual perceptual experience. For what it's worth I think that it may be possible to represent ethical properties in audition, e.g., I could hear her demeaning tone. 
Proponents of Ethical Perception think that agents can sometimes literally see the instantiation of ethical properties. This should be distinguished from the view that we can see scenarios that, as a matter of fact, instantiate ethical properties (de re ethical perception). Ethical Perception captures the idea that, even if we assume an intimate connection between ethical properties and non-ethical natural properties, e.g., reduction or exhaustive constitution, one could only be said to have an ethical visual experience by visually representing the instantiation of ethical properties. ${ }^{14}$

Ethical Perception can be motivated by appeal to the phenomenology of ethical experience. Cat is one case among many. Here is another:

Change of Subject: Mary is in the restaurant with her friends celebrating her birthday. As the centre of attention she is enjoying being teased. But then the teasing begins to get a bit too much for her, and she starts to get upset. She is about to cry. Jack, who is a kind person, recognises that Mary is getting needlessly upset and is about to cry, and he immediately changes the subject. The awkward moment is passed, and Mary is happy again. ${ }^{15}$

In this case, the phenomenology of Jack's recognition of Mary's plight can be reasonably described perceptually, i.e., as seeing an ethical 'affordance' of the situation (similar to 'edibility'); that Mary can be helped or the to-be-doneness of a particular action.

Support for Ethical Perception can also be garnered from the aforementioned high-level view of perceptual content: if perceivers can represent, e.g., natural kinds, in experience, then it is perhaps less incredible to think that agents can have experiences of wrongness, or ethical affordances.

\footnotetext{
${ }^{14}$ Although Ethical Perception would seem to be of primary appeal to Ethical Naturalists two things should be kept in mind: (i) there is no consensus on how best to characterise 'natural', and (ii) McBrayer (2010a) has plausibly argued that Ethical Perception is compatible with some form of non-naturalism.
}

15 From Goldie 2007, p. 1 
However, the principal motivation for defending Ethical Perception is that it promises to support a version of Perceptualism.

Perhaps the most well-known form of Perceptualism is in the Virtue Ethics tradition. ${ }^{16}$ Some modern Virtue Ethicists conceive of the virtuous agent as possessing a perceptual ability which is the product of habituation. On this view, the virtuous person can just 'see' what to do, and is appropriately motivated by what they can see. More specifically, seeing which of the potentially actionrelevant features of a given scenario is "salient" apparently necessitates motivation, silencing other considerations. On some views (see especially, Little and McDowell) ethical 'vision' is motivating due to its being tied to a "conception of how to live" which is distinctive of the virtuous agent.

Although a prominent version of Perceptualism, there is an important question as to whether the Virtue Ethicists's perceptual model is merely figurative. One way in which it could be is if the appeal to 'ethical perception' is simply a way of capturing some perceptual-like aspects of the virtuous agent's ability, e.g., the non-inferential character of their judgments, and the resistance of their ability to propositional capture, say, as a stock of general ethical principles. On this sort of view, the perceptual ability is just a sort of recognitional ability (cf. Dancy 1993 on a "contentless ability to discern reasons" ${ }^{17}$ ) which issues in ethical judgment and action.

Another, perhaps less metaphorical, model ${ }^{18}$ involves cashing the virtuous agent's perceptual ability in terms of emotional responses. On this sort of view, the virtuous agent's affective dispositions constitute their 'seeing' what situations demand, motivating them appropriately: the virtuous can "see the demands of

\footnotetext{
16 See, e.g., Goldie 2007, Little 1997, Lovibond 2002, McDowell 1998, Murdoch 1970. Here I focus on NeoAristotelian brands of virtue ethics. I discuss Murdoch, who is harder to place, in §3.

17 Dancy is not a virtue ethicist, but is committed to a particularist epistemology.

18 For the view that emotions are perceptions see Doring 2003 and Prinz 2004. For criticism, see Brady 2013.
} 
kindness by feeling them." 19 This emotional model could be freestanding or serve as a compliment to the recognitional model, e.g., the virtuous agent's recognitional ability might be a partial product of the training of their affective responses, some of which may be due to imaginative engagement (cf. Goldie 2007).

Despite the existence of these models, Virtue Ethicists might be motivated to defend Ethical Perception as a more 'robust' way of cashing out ethical virtue: virtuous agents experience the instantiation of ethical properties. I assess cognitive penetration's bearing on the prospects for Virtue Ethics in $\S 3$.

Another version of Perceptualism can be found among Cornell Realists. ${ }^{20}$ Cornell Realists share a commitment to the metaphysical view that, although ethical properties are not reducible (analytically or non-analytically) to other natural properties, they are themselves natural properties. The distinguishing feature of Cornell Realism, however, can be found in their epistemological outlook. Inspired by developments in the philosophy science, Cornell Realists draw a parallel between the supposed theory-ladenness of scientific judgment and observation with that of ethical judgment and perception. Proponents claim that ethics is, like other sciences, autonomous in the following sense: just as there is no reasonable inference from non-biological evidence to biological claims (absent some background theory), there is no reasonable inference from non-ethical evidence to ethical conclusions. Ethical judgments and evidence must always be assessed in the context of other ethical judgments.

However, just as theory-ladenness doesn't preclude an important role for scientific observation and intuition, Cornell Realists think that there is such a thing as ethical perception: "people can observe - that is, see with their eyes that good or bad things are happening, that someone is doing something wrong,

\footnotetext{
19 Jacobsen 2005, p. 393.

20 See, e.g., Boyd 1988, Brink 1989, and Sturgeon 2002. They all taught or studied at Cornell University.
} 
and the like"21. Like scientific observation, ethical perception can sometimes make explicit what agents were perhaps unconsciously committed to, but is best understood as involving a sort of inference: it is "automatic and unconscious, and among the premises are moral views one already has." 22 This lends itself to an inferentialist epistemology for ethical observation (more on the distinction between inferential and non-inferential justification below).

Although it is not entirely clear whether Cornell Realists intend talk of ethical perception to be taken literally, they might be attracted to defending a version of Ethical Perception as a way of supplementing their view. I assess the bearing of cognitive penetrability on Cornell Realism when I discuss the epistemology of cognitively penetrable ethical experience in $\S 4$.

The final brand of Perceptualism that I discuss is that held by some Ethical Intuitionists. ${ }^{23}$ Intuitionism is minimally the view that there are at least some noninferentially justified ethical beliefs. On one popular (and permissive) view, S's belief that $p$ is non-inferentially justified iff $S$ 's belief that $p$ is justified and $S$ hasn't inferred (either explicitly or implicitly) $p$ from another belief. A more restrictive account assumes that $S$ 's belief that $p$ is non-inferentially justified iff $S$ 's belief that $p$ is justified independently of $S$ having justification for believing propositions other than p. Although the view has been associated with metaphysical views like non-naturalism, the view is compatible with reductive and non-reductive forms of naturalism. Like Cornell Realists, Intuitionists think that ethical claims cannot be inferred from purely non-ethical premises; however, unlike Cornell Realists, they are keen to defend the theory-independence of ethical judgments, a feature they associate with non-inferential justification. ${ }^{24}$

\footnotetext{
21 2002, p. 205

22 lbid, p. 205

23 See, e.g., Audi 2013, Prichard 1912, Ross 1930.

24 See Audi 2004 for a statement of this.
} 
If one was attracted to ethical naturalism and wanted to defend an Intuitionist epistemology, then Ethical Perception might be appealing since it could potentially ground Perceptual Intuitionism: ethical agents can have noninferentially justified ethical beliefs on the basis of ethical experience. Such a view could plausibly constitute an independent a posteriori alternative to a priori and affectual Intuitionist accounts, whilst sidestepping worries that Intuitionism requires positing some dedicated ethical faculty (see Mackie 1977).

However, in order to do so, the non-inferential justification that ethical experience confers must not be of an epistemically dependent sort:

Epistemic Dependence: A state or process, e, epistemically depends upon another state, $d$, with respect to content $c$ iff state or process $e$ is justified or justification-conferring with respect to c only if (and partly because) $d$ is justified or justification-conferring with respect to $c$.

To understand how a belief might be non-inferentially justified but be derived from an epistemically dependent source consider that on one plausible view of memory - Preservationism ${ }^{25}$ - remembering is an epistemically dependent source of justification, even if memorial beliefs are non-inferentially justified. That is, memorial beliefs are justified only if the subject previously had some nonmemorial justification for the belief.

If ethical experience is epistemically dependent, then this would undermine the prospects for an independent a posteriori Intuitionist account because the view would be importantly incomplete: we would still be owed an account of an 
epistemically independent source of non-inferentially justified ethical beliefs, and this might require appealing to intuition or emotion as epistemic sources. ${ }^{26}$

So for Ethical Perception to hold significance for an independent Perceptual Intuitionism, ethical experience should be epistemically independent. I assess whether a cognitive penetration model of Ethical Perception can deliver this in §4.

As should be clear, Ethical Perception could provide support for varieties of Perceptualism. In the next section I provide some reason to think that a cognitive penetration model of Ethical Perception is most promising.

\section{Towards the Cognitive Penetration Model}

Independently of any particular ethical view, are there any reasons for thinking that a cognitive penetration model is likely to be the most plausible way of accounting for Ethical Perception? In this section I suggest an affirmative answer.

An alternative model of Ethical Perception that someone might defend is what I call the 'Intra-Perceptual Model'. On this view, ethical experience is made possible by learning involving an "associative process that takes place solely within the visual system". 27 Ethical perceptual learning would be due to repeated exposure to ethical sensory stimuli and top-down processing within the system, with the result that agents are able to represent the instantiation of ethical properties in experience.

For example, perhaps my being repeatedly exposed to cases of suffering has meant that my visual system has come to classify certain low-level properties under the category SUFFERING. Through a similar process, it may also have come to

\footnotetext{
26 Two other possibilities: suppose that ethical experiences were epistemically dependent upon inferentially justified beliefs. For epistemological reasons, it would seem odd to call the resulting view 'Intuitionist' (this might be due to its association with Foundationalism - note, however, that the views are, strictly-speaking, distinct). Further, if ethical experience were epistemically dependent upon ethical testimony then this raises worries about a regress of ethical testimony, as well as concerns about subject's entitlement to ethical beliefs held on the basis of testimony. See Hopkins 2007 for the view that ethical testimony doesn't confer entitlement to ethical belief.
}

${ }_{27}$ Macpherson 2012, p. 33. Of course, we need not limit this model to vision. 
classify certain cases of suffering under the category WRONGNESS. As a result, when confronted with the Cat case, I might visually represent the wrongness of what the youths are doing, where this is due to a process of learning that takes place within the visual system itself.

An objection: unless the perceptual system is in some sense hard-wired for ethical representation - as is plausibly the case for colours and shapes - it is hard to see how the perceptual system could come to classify certain stimuli under ethical categories by itself, i.e., in the absence of cognition. Furthermore, ethical perceptual representation is not hard-wired, so the view is a non-starter.

In response, a proponent of the Intra-Perceptual model who accepts this general point (i.e., that perception couldn't come to classify stimuli under ethical categories by itself without ethical representation being hard-wired) ${ }^{28}$, should claim that it is perhaps not implausible to think that the perceptual system of ordinary human beings could come purpose built for ethical representation. This is because it fulfills a plausible necessary condition for being hard-wired. Consider the following from Macpherson (2012):

"the cognitively unadulterated system will have limited representational powers - no doubt powers to represent only that which is likely to be encountered by most humans in different locations and at different times powers that are likely to be useful to all. These representational powers will extend to properties such as shape, colour and size". 29

The point of interest here is that it is not implausible to think that the power to perceptually represent ethical properties, e.g., wrongness, might be useful for humans in most environments they are likely to find themselves in. Given that a capacity to perceptually detect ethical properties could alert perceivers to the

\footnotetext{
28 For doubts about this see Pylyshyn, 1999 p. 361

29 Macpherson, 2012, p. 33
} 
presence of threats or potential cooperative partners, it could have considerable fitness value. Perhaps the Intra-Perceptual model is not so far-fetched after all.

There are two things to say in response. Firstly, the claim that a disposition to represent ethical properties might be useful to most subjects in various environments may be disputed. One thought is that if a disposition to represent ethical properties is already 'hard-wired' in other systems, e.g., the emotional system, then there would be no obvious evolutionary point to perceptual hardwiring too. Secondly, even if one accepted the point about the utility of ethical perceptual representation, it is important to stress that Macpherson's condition is only a necessary condition for perceptual hard-wiring, and hence support for the model might remain weak (it couldn't be a sufficient condition: it may be useful for everyone to have $\mathrm{x}$-ray vision, but alas, we don't).

One additional, and important, reason to think that the Intra-Perceptual model couldn't be the whole story (or any of it) in accounting for Ethical Perception is that it might be overly restrictive. For recall that the model requires that we are repeatedly perceptually exposed to ethical scenarios. However, we might think that an ethical perceiver's capacities for ethical perceptual representation could outstrip cases that they happen to have encountered perceptually in the past, e.g., they may simply have imaginatively entertained cases. This might suggest that we need to appeal to influences from cognition in order to account for Ethical Perception.

All of this might lead us to think that appealing to cognitive penetration is a more promising way of accounting for Ethical Perception. In any case, commentators and proponents of Ethical Perception have tended to assume that some sort of cognitive and conceptual sophistication are required for ethical experience. ${ }^{30} \mathrm{I}$ suspect that a reason for this is that discussions may be assuming that versions

\footnotetext{
30 See, e.g., Vayrynen 2008 and Cullison 2010. Cullison appears to appeal to cognitive sophistication to deal with the 'Morally Blind' objection to Ethical Perception.
} 
of Perceptualism presuppose this, e.g., the Virtue Ethicist's emphasis upon habituation, Cornell Realism's emphasis on theory-ladenness.

It is worth noting a possible third way between the two models considered. On the 'Hybrid' model I have in mind, a process of intra-perceptual learning gets kickstarted by cognitive penetration. ${ }^{31}$ This could avoid claiming that the perceptual system comes hard-wired for the representation of ethical properties, whilst affording cognition an important role. Due to space constraints, in what follows I will primarily focus on the simple or 'synchronic' cognitive penetration model, but will highlight the potential significance of the Hybrid model when appropriate.

Before proceeding to consider the implications of the cognitive penetration model for the varieties of Perceptualism, I will briefly relate cognitive penetration and Ethical Perception to Robert Audi's 32 recently presented 'Integration' model of ethical experience which some metaethicists may be more familiar with.

According to Audi, ethical perception involves what he calls the "phenomenal integration' of a perception of non-moral base properties (upon which some moral property, e.g., wrongness, is consequential ${ }^{33}$ ) and some moral 'experiential' or 'phenomenal' element. Examples of the latter include "a phenomenal sense which may, but need not, be emotional - of the moral character of the act" 34 , an "intuitive sense of wrongdoing" 35 , a nonconceptual "sense of unfittingness" 36 , or a "perceptual moral seeming"37. If one thought that there is such a thing as cognitive phenomenology, one might also include ethical judgments (inferential or non-inferential) as potential components in Integrated experiences.

\footnotetext{
31 See Cecchi, A., forthcoming, for an account of what he calls diachronic cognitive penetration.

32 See his 2013, Moral Perception.

${ }_{33}$ One could presumably hold a reductionist view whilst still endorsing the Integration model.

${ }^{34}$ Moral Perception, p. 40

$35 \mathrm{Ibid}$, p. 43

36 Ibid, p. 46

37 Ibid. p. 46
} 
Integration sounds like cognitive penetration. However, Audi doesn't connect the two. Indeed, for all Audi says, Integration is compatible with the following process: Integration doesn't involve the contents of perceptual experience being altered by the moral 'experiential element', but rather, leads to the formation of an overall experience which is the amalgam of non-ethical perceptual experience and the experiential element. Strictly speaking, that wouldn't involve cognitive penetration because it doesn't involve the alteration of perceptual contents and/ or character by cognition. Indeed, this interpretation of Integration wouldn't actually deliver an account of Ethical Perception.

We have some reason to think that the cognitive penetration model of Ethical Perception is the most promising of those considered. On that assumption I consider implications of this model for the varieties of Perceptualism, beginning with Virtue Ethics.

\section{Cognitive Penetration and Virtue}

Can a cognitive penetration model of Ethical Perception capture the important aspects of virtuous agency, i.e., their 'perceptual' ability and its connection with motivation? ${ }^{38}$ Can it do so in a superior way to extant models?

One way to model Ethical Perception would be to claim that cognitively penetrated ethical experience were parasitic upon either or both of the alternative models, i.e., ethical experiences are facilitated by cognitive penetration by either (i) noninferential judgments, e.g., 'Mary is distressed and needs helping', constitutive of the virtuous agent's recognitional ability, or, (ii) emotional responses, e.g., compassion, which would otherwise directly yield ethical judgment and motivate action. This Parasitic Cognitive Penetration model would clearly not require fewer theoretical commitments than the judgment and emotional models. I will consider whether the model could yield theoretical benefits shortly.

\footnotetext{
${ }^{38}$ As I'm characterising the view, Virtue Ethicists are not committed to a particular thesis about the epistemic status of 'perceptual' judgments, e.g., although they are psychologically non-inferential, they could be epistemically inferential.
} 
Could there be a Non-Parasitic cognitive penetration model? One thought might be that the virtuous agent's recognitional ability (their 'contentless ability to discern reasons', to employ Dancy's phrase) could directly influence the contents of their experience, rather than its being mediated by judgments that are the direct result of the ability. In a recent paper, Nico Silins ${ }^{39}$ discusses the idea that something like a recognitional ability might facilitate high-level perception. However, depending on how we fill in the details of the virtuous agent's 'contentless' recognitional ability - including whether this would count as a cognitive capacity, as opposed to a perceptual one - we might doubt that this constitutes a cognitive penetration model of Ethical Perception.

An alternative Non-Parasitic model might appeal to cognitive penetration of perception by what Little and McDowell refer to as the virtuous agent's "conception of how to live." This is supposed to play a key role in motivating the virtuous agent (it is, according to McDowell, an 'orectic state'), but apart from that it is not entirely clear what a conception of how to live is supposed to be. Here is a suggestion: perhaps the virtuous agent's conception of how to live is constituted by the totality of interdependent ethical and non-ethical beliefs, emotional dispositions, experiences, that together shape the way they 'ethically' see the world. This overall conception - which should not be confused with a codified and hierarchical system of principles - might cognitively penetrate their experience. Perhaps this Non-Parasitic model could deliver on the 'perceptual' aspects of the Virtue Ethicist's model of the virtuous agent.

Before considering how these cognitive penetration models compare to extant judgment and emotional models, it is important to note one limitation of all cognitive penetration models for explicating the perceptual capacities of virtuous agents. One feature of the virtuous agent appears to be their attentiveness to ethically relevant features in the world. Recall the 'Change of Subject' example. In the example, Jack - a kind person - discerns Mary's emotional vulnerability and 
the to-be-doneness of a particular action of kindness. We might expect that, quite generally, a kind person will be visually attentive to emotional signals in those with whom they engage. They are 'on the look out' for these sorts of signs. In such cases perception plays an important role in facilitating virtuous action. However, on standard conceptions, a cognitive state impacting on the subject's attention does not get to count as an instance of cognitive penetration. ${ }^{40}$ Such virtuous patterns of attention do not appear to be captured by a cognitive penetration model.

Putting this limitation aside, do cognitive penetration models have any clear-cut theoretical benefits over others? When considering Parasitic models, the answer seems to be quite clearly 'no'. As was noted, this model will inherit the theoretical costs of judgment and emotional models. It also saddles proponents with the burden of defending high-level perceptual contents, e.g., affordances. The only way in which the Parasitic model would have a clear theoretical advantage would be if there were some benefit for Virtue Ethicists to positing literal ethical perception. However, it is unclear whether a more literal understanding of the virtuous agent's perceptual capacity (i) is actually more literal, since emotions may be perceptual experiences, and, (ii) captures better the sorts of features that motivated talk of ethical 'seeing' in the first place, e.g., uncodifiability. Further, perception doesn't obviously have a comparatively more intimate connection with motivation that judgment and emotion ${ }^{41}$ lack (indeed, emotions appears to be more plausible candidates for motivating states). Hence, it is unclear what reasons there are for defending a Parasitic model.

Although the Conception of How To Live model doesn't obviously inherit the theoretical burdens of extant judgment and emotional models, it should hopefully be clear from the previous discussion that enthusiasm for such a model should be muted. It is simply unclear whether a theoretical advance for Virtue Ethics is made

\footnotetext{
40 Although see Lyons 2011 for a contrary view.

41 A candidate emotional state for some of the cases we are interested in - those involving perception of tobe-doneness - might be what Mandelbaum 1969 referred to as felt-demand.
} 
by appealing to literal ethical perception and cognitive penetration. That, of course, doesn't mean that a cognitive penetration model is bogus. It simply means that Virtue Ethicists shouldn't get too excited about a version of their view grounded (at least partially) in a cognitive penetration model of Ethical Perception.

Before ending, let me briefly discuss the work of Iris Murdoch, which can be thought of as part of the Virtue Ethics tradition. Murdoch famously places much ethical importance on our capacity to 'see' the 'reality' of other people. However, as with other Perceptualists, it isn't always clear whether this is to be thought of as merely metaphorical (she often speaks of the 'metaphor' of vision). In any case, this much is clear: 'moral vision' - roughly, seeing people 'justly and lovingly' involves cognitive activity such as "moral imagination and moral effort" 42 , facilitating shifts (perhaps best thought of as gestalt shifts) in the way an individual is conceptualised. This sits well with a cognitive penetration model of Ethical Perception since ethical vision is facilitated by a cognitive process. However, on my reading, Murdoch thinks of the 'moral effort' involved in gazing upon the other as a primarily cognitive effort. Ethical Perception, as it is being conceived in this paper, appears to only be the product of this process of attending to others. Hence, its significance for explicating Murdoch's view might be limited.

In the following section I consider the epistemology of cognitively penetrable ethical experience. In doing so I clarify whether the model best supports Cornell Realism or Perceptual Intuitionism.

\section{The Epistemology of Cognitively Penetrable Ethical Experience}

Cornell Realists and Perceptual Intuitionists both afford an important role to ethical experience. However, they appear committed to divergent views about the epistemology of such experiences. While Cornell Realists stress the theorydependence and epistemically inferential nature of ethical observation, Perceptual Intuitionists favour theory-independence and epistemically independent non- 
inferential justification. In this section I consider which of these is best supported by a cognitive penetration model of Ethical Perception, by consideration of the epistemology of ethical experience. I argue that Cornell Realism is best supported by the model.

In order to make discussion tractable, I will characterise the disagreement among the two camps as concerning whether ethical experience is epistemically dependent upon its penetrator(s). Recall:

Epistemic Dependence: A state or process, e, epistemically depends upon another state, $d$, with respect to content $c$ iff state or process e is justified or justification-conferring with respect to c only if (and partly because) $d$ is justified or justification-conferring with respect to $c$.

Some clarification of Epistemic Dependence. This does not entail that a justification-conferring penetrating state is sufficient to enable the penetrated ethical experience to confer justification, merely that it is necessary. Perhaps the transition between states must be quasi-inferential: analogous to that involved in a paradigm case of good inference (see, e.g., McGrath 2013). Epistemic Dependence is also compatible with it being true that some (perhaps all) cognitively penetrated ethical experiences do not confer any justification, even if the penetrating state is justified. Also, Epistemic Dependence is compatible with the view that experiences which are penetrated by unjustified states could confer some limited justification, but not enough for outright justified belief. Finally, Epistemic Dependence will likely only obtain with respect to specific contents, e.g., it is most plausible that it could hold with respect to first-order ethical contents attributing ethical properties to objects, persons and events in the world. 
Prima facie, it may seem that, given their stress on the theory-ladenness of observation, a cognitive penetration model of Ethical Perception will sit best with Cornell Realism. ${ }^{43}$

Some degree of theory-ladenness entails a causal dependency of experience upon background beliefs. But for cognitive penetration to support Cornell Realism it must also be the case that ethical experience is epistemically dependent upon the background 'theory' that facilitates it (by cognitive penetration). That needs to be argued for. I now argue for the conclusion that at least some theory-dependent ethical experience is epistemically dependent.

To focus discussion, consider again the Cat example, but suppose that the experience is cognitively penetrated by a cluster of unjustified beliefs - an ethical 'theory' - concerning the wrongness of torturing sentient beings (I'll leave it to the reader to invent some reason why the beliefs are unjustified).

One reason to think that the experience couldn't confer justification for ethical belief, e.g., that what the youths are doing is wrong, is that it seems intuitive that, with respect to this ethical content, the experience would inherit the dubious epistemic status of the penetrating beliefs. Call this the ED Intuition. Something like a 'rubbish in, rubbish out' 44 principle might underlie it.

In order to provide further support for this, we might say that the process of cognitive penetration (in the ethical case) is analogous to the processes of belief preservation (as occurs in memory) and/or inference (where we progress from premises to a conclusion), which both plausibly instantiate an epistemic

\footnotetext{
43 Note, however, that a commitment to theory-ladenness is typically understood as a stronger thesis than the Cog-Pen Thesis, since it tends to be associated with the view that perception is continuously and thoroughly penetrated, potentially by arbitrarily much of the subject's beliefs and commitments. Proponents of the Cog-Pen thesis need not commit themselves to this, e.g., they could claim that experience is only penetrated in cases of expertise. I largely ignore this complication in what follows, but it is worth considering whether the Cog-Pen thesis is relevant to Cornell Realism in light of it.
}

44 This moniker comes from Silins, 2013. 
dependence relation. ${ }^{45}$ Hence, we have good defeasible reasons for thinking that cognitively penetrated ethical experiences are also epistemically dependent.

However, this won't impress Perceptual Dogmatists, ${ }^{46}$ according to whom experiences, no matter what their etiology, can confer defeasible justification for belief. They will respond that this treats experience as if it were just like belief, when they are importantly different. On this view, the justification-conferring power of perceptual experience comes from its presentational phenomenology. So we have reason to resist the ED Intuition since it rests on/or is expressive of a bogus view of perceptual epistemology.

In order to evaluate this for ethical experience, it is worth considering what is meant by presentational phenomenology. Chudnoff (2011) gives the following characterisation:

"suppose you look at a car and you seem to see that it is red. Further you seem to see its colour - its redness. In this case you seem to see that $p$ that your car is red - and you seem to see an item - your car's redness that makes it true that p. I take this to be an example of presentational phenomenology. More generally: if your perceptual experience is one in which it both seems to you that $p$ and in which you seem to be sensorily aware of an item that makes it true that $p$, then I will say that your experience has presentational phenomenology with respect to $p . "$

Now consider the case of Cat, and suppose that the relevant seeming is that what the hoodlums are doing is wrong. It is plausible that you are not perceptually aware of an item that makes it the case that what the hoodlums are doing is wrong (all-things-considered), despite their setting fire to Cat being a good

\footnotetext{
45 See Siegel 2013 and Vance forthcoming for discussion.

46 See Huemer 2007, Pryor 2000, 2004. I am using the Perceptual Dogmatist as a representative opponent.
} 
indicator of wrongness. ${ }^{47}$ Hence, your experience doesn't have presentational phenomenology with respect to wrongness content. If that's right, then this might lead us to downplay the role of phenomenology in ethical experience (at least with respect to certain ethical contents), and pay more attention to the etiology of experience, i.e., this might make us treat these cases more like that of belief.

Supposing, however, that one rejected this response. Vance (forthcoming) has pointed out that at least some experiences which apparently have presentational phenomenology - cognitively penetrated emotional experiences - are epistemically dependent on their penetrators. ${ }^{48}$ That is, there are some cases where an emotional state, e.g., fear, which is cognitively penetrated by an unjustified belief, is, because of this causal influence, itself unjustified.

A Dogmatist might respond here by claiming that if emotions are experiences then they aren't capable of being justified/unjustified. However, in doing so they will be going against the consensus in the epistemology of emotion. ${ }^{49}$ Another option for the Dogmatist would be to try to identify some difference between perceptual experience and emotion. Here is one suggestion: perhaps we have greater control over emotional experience as compared with perceptual experience ${ }^{50} \mathrm{~A}$ brief response: assuming that ethical experience is facilitated by cognitive penetration, it is not at all obvious that we do have a lesser control over our disposition to be in ethical perceptual states, given certain stimuli, compared with our disposition to be in emotional states. Both would seem to be susceptible to a (limited) degree of diachronic control.

\footnotetext{
47 A similar point can be made about Change of Subject and the perception of ought-to-be-doneness. However, one might think it more plausible that perceptual experiences could have presentational phenomenology with respect to thick ethical properties (those picked out by thick concepts), e.g. cruelty. A similar point could be made about prima facie wrongness in Cat.

48 Note that my notion of epistemic dependence is narrower than his. Also, I must confess that it is not obvious to me that emotional experiences do have presentational phenomenology, at least in Chudnoff's sense. Note, however, that Vance may only speaks of the feeling that $p$ is revealed to the subject.
}

49 See, e.g., Brady, 2007, de Sousa 1987, Doring 2003

50 See Tappolet 2012 for this view. 
Together, we might think that these considerations constitute a strong case for thinking that cognitively penetrated ethical experience is epistemically dependent. Hence, we might think that a cognitive penetration model provides some limited ${ }^{51}$ degree of support for Cornell Realism over Perceptual Intuitionism.

However, at this point, Perceptual Intuitionists will protest: ethical judgment and, by extension, ethical perception - is very often theory-independent. Even if theory-dependent ethical experience is epistemically dependent, we shouldn't assume that theory-independent experience is.

I now show that cognitive penetration doesn't support Perceptual Intuitionism even if we grant that ethical experience is sometimes theory-independent. For even if cognitively penetrated ethical experience is theory-independent, it will have to be causally dependent upon some penetrating state(s). Here are some candidate penetrators in theory-independent ethical experience: emotions, intuitions and desires. ${ }^{52} 53$

To illustrate, suppose that in Cat, my horror at the scene before me penetrates my experience. Insofar as one thinks that the perceptual experience could confer any justification (and that's not obvious), it seems that it would be epistemically dependent on the emotional experience, i.e., if the emotion was for some reason unjustified, then the perceptual experience couldn't confer justification. A similar result seems plausible if we replace the emotion of horror with the intuition that what the youths are doing is wrong.

\footnotetext{
51 I have not shown that the transition from the background theory to ethical perception involves a sort of inference as, e.g., Sturgeon, seems to think.

52 Appealing to these states could perhaps best explain cases where ethical experience seem to run counter to our ethical beliefs, e.g., cases of ethical conversion. See Orwell's "A Hanging" for an actual case of this.

53 One might also include here a conception of how to live, ethical concepts, and imaginative states. In the case of a conception of how to live it is not entirely clear why this can't be rationally assessed, e.g., for justifiedness, or its capacity to confer justification. The case of ethical concepts and imagination are trickier cases, which unfortunately I don't have space to consider.
} 
A note about desires: an experience that is cognitively by desire is thought to constitute a paradigm case of perceptual experience that fails to justify belief with respect to some of its contents. That's because it involves wishful thinking (seeing), and wishful thinking can't justify you in believing anything. Here is Stokes (forthcoming):

"plausibly, if a perceptual experience is cognitively penetrated by desire or some other orectic mental state-importantly, such that the experience would not be had without that desire-then that experience cannot justify a belief or provide knowledge." 54

However, it is worth noting that some philosophers, e.g., Oddie (2005), think that desires represent their objects as good, and that they can justify beliefs with this sort of content. It is a further question whether all desires can defeasibly justify these sorts of beliefs, or whether there are constraints on what constitutes a justified desire, e.g., to do with their etiology or their content. ${ }^{55}$ Whatever account of desires we opt for, it seems plausible that the desire would have to be itself justified or justification-conferring in order for the penetrated ethical experience to be capable of justifying.

To further support the idea that even these theory-independent cognitively penetrated experiences are epistemically dependent, consider again Audi's Integration model. Recall that on a non-cognitive penetration interpretation, Integration involves the amalgam of a non-ethical perceptual experience and 'ethical phenomenal sensing', e.g., intuitions and emotions). Two points: firstly, it seems plausible that an overall experience, of which ethical sensing supplies the 'ethical' component, would be epistemically dependent on ethical sensing, i.e., if ethical phenomenal sensing doesn't justify, then it is hard to accept that the overall experience could (with respect to ethical contents). Secondly, the present suggestion is that theory-independent penetrated ethical experience is relevantly

\footnotetext{
54 Stokes, p. 13

55 See Parfit 2012 for discussion.
} 
similar to a (non-penetrated) integrated experience. Hence if you think the latter are epistemically dependent on their constituents, you have reason to think that the former are dependent on their penetrators.

If this is all correct, then it seems that we have good reasons for thinking that at least some, and perhaps all, cognitively penetrated ethical experiences are epistemically dependent. What are the implications for Perceptual Intuitionism and Cornell Realism?

Firstly, Perceptual Intuitionism: even if there are some theory-independent, noninferentially justified beliefs on the basis of ethical experience, it seems that an independently plausible Perceptual Intuitionism may not be supported by a cognitive penetration model due to epistemic dependence. Proponents may need to give an account of emotional, orectic, or a priori sources of justification.

Does that mean that Perceptual Intuitionism is in trouble? Not necessarily. Firstly, one might be sanguine about a version of Perceptual Intuitionism which relies upon more 'basic' sources of ethical justification. One might adapt the account presented by Audi (2013) along these lines. Secondly, although I suggested that a cognitive penetration model is most plausible, it is open to Perceptual Intuitionists to defend an Intra-Perceptual Learning or Hybrid account. Indeed, these accounts might sit better with their commitment to theory-independence (and, perhaps, epistemic independence). Finally, Perceptual Intuitionists might try to ground a version of their view which doesn't require Ethical Perception: this could involve defending a non-inferential 'recognitional ability' view similar to that discussed in $\S 3$. However, such a model could face problems to do with epistemic dependence. ${ }^{56}$

\footnotetext{
56 These alternative models might be appealed to to supplement the cognitive penetration model, i.e., some ethical experiences are facilitated by penetration from beliefs based upon ethical experiences brought about by Intra-Perceptual Learning, diachronic cognitive penetration, or a non-inferential recognitional ability. Note, however, that this would still be to concede that cognitive penetration doesn't support Perceptual Intuitionism since penetrated experiences are epistemically dependent.
} 
Turning now to Cornell Realists: by focusing on theory-laden penetrated experiences, things might look promising. Such experiences seem to be epistemically dependent and the resulting perceptual beliefs would seem to be inferentially justified (at least on restrictive accounts of non-inferential justification), as Cornell Realists would be expected to claim. In response to the Intuitionist's claim that there are 'theory-independent' experiences Cornell Realists will have to claim that these are really theory-dependent, or, that the states which facilitate them, e.g., intuitions or emotions, are themselves theorydependent. This is, of course, a controversial claim amongst ethicists in a way that an analogous claim for scientific observation is less so. Resolving this issue is, unfortunately, far beyond the scope of this essay.

\section{Conclusion}

In this paper I considered the implications of a cognitive penetration model of Ethical Perception for three varieties of Perceptualism. I argued that, although the model may constitute an additional/alternative way for Virtue Ethicists to explicate virtuous agency, it doesn't constitute a theoretical advance over extant models. I then argued that, given that cognitively penetrated ethical experience (theory-dependent or independent) appears to be epistemically dependent, this favours Cornell Realism over Perceptual Intuitionism.

It should be borne in mind that all of these conclusions are hostage to there being empirical evidence supporting (i) the existence of 'ethical' cognitive penetration, and, (ii) the specific kinds of cognitive penetration posited by the varieties of Perceptualism. To illustrate (ii): it may turn out that there is never cognitive penetration by a conception of how to live.

Finally, we should remember that cognitive penetration may not be necessary for Ethical Perception, or indeed for Perceptualism. Its significance should not be overstated. 


\section{Bibliography}

Audi, R. (2004). The Good in the Right: A Theory of Intuition and Intrinsic Value. Princeton University Press

Audi, R. (2013). Moral Perception. Princeton University Press

Boyd, R. [1988] (2007). How to be a Moral Realist. In Shafer-Landau, R. \& Cuneo, T. (eds.), Foundations of Ethics An Anthology. Blackwell

Brady, M.S. (2007). Recalcitrant Emotions and Visual Illusions. American Philosophical Quarterly 44 (3): 273-284

Brady, M.S. (2013). Emotional Insight. OUP

Brink, D. (1989). Moral Realism and the Foundations of Ethics. Cambridge University Press

Bruner, J. S., \& Goodman, C. C. (1947). Value and need as organizing factors in perception. Journal of Abnormal and Social Psychology, 42, 33-44.

Cecchi, A. (forthcoming). Cognitive Penetration and Neural Plasticity. Dialectica.

Chudnoff, E. (2011). What intuitions are like. Philosophy and Phenomenological Research 82 (3): 625-654

Cowan, R. (forthcoming a). Perceptual Intuitionism. Philosophy and Phenomenological Research.

Cowan, R. (forthcoming b). Clarifying Ethical Intuitionism. European Journal of Philosophy.

Cullison, A. (2010), Moral Perception. European Journal of Philosophy 18 (2): $159-175$

Dancy, J. (1993), Moral Reasons. Oxford Blackwell

Delk, J. L. and Fillenbaum, S. (1965). Differences in Perceived Colour as a Function of Characteristic Colour. The American Journal of Psychology, 78(2): 290-93

de Sousa, R. (1987). The Rationality of Emotion. Cambridge, MIT Press

Döring, S. (2003). Explaining Action By Emotion. The Philosophical Quarterly 53 (211): 214-230

Goldie, P. (2007). Seeing What is the Kind Thing To Do. Dialectica. 
Hansen, T., M. Olkkonen, S. Walter \& K.R. Gegenfurtner. Memory modulates color appearance. Nature Neuroscience 9 (2006) 1367-8.

Harman, G. (1977). The Nature of Morality: An Introduction to Ethics. New York: Oxford University Press

Hopkins, R. (2007). What's wrong with moral testimony?. Philosophy and Phenomenological Research 74 (3): 611-634.

Huemer, M. (2007). Compassionate phenomenal conservatism. Philosophy and Phenomenological Research, 74(1), 30-55.

Jacobsen, D. (2005). Seeing by Feeling: Virtues, Skills and Moral Perception. Ethical Theory and Moral Practice 8: 387-409

Little M. (1997). Virtue as Knowledge. Nous 31(1), 59-79

Lyons, J. (2011). Circularity, reliability, and the cognitive penetrability of perception. Philosophical Issues, 21(1), 289-311.

Mackie, J.L. (1977). Ethics: Inventing Right and Wrong. Hammondsworth: Penguin

MacPherson, F. (2012). Cognitive penetration of colour experience: Rethinking the issue in light of an indirect mechanism. Philosophy and Phenomenological Research, 84(1), 24-62.

Mandelbaum, M. (1969), The Phenomenology of Moral Experience, Baltimore: John Hopkins University Press

McBrayer, J. (2010a). Moral Perception and the Causal Objection. Ratio 23 (3): 291-307

McBrayer, J. (2010b). A Limited Defense of Moral Perception. Philosophical Studies 149 (3)

McDowell, J. (1998), Value, Mind, and Reality. Princeton Press

McGrath, S. (2004). Moral Knowledge by Perception. Philosophical Perspectives 18 (1): $209-228$

Millar, A., (2000). The Scope of Perceptual Knowledge. Philosophy 75 (291): 73-88

Murdoch, I. [1970] (2001). The Sovereignty of Good. Routledge

Oddie, G. (2005). Value, Reality and Desire. Oxford University Press

Prinz, J. (2004), Gut Reactions: A Perceptual Theory of the Emotions, Oxford University Press

Pryor, J. (2000). The skeptic and the dogmatist. Nous, 34(4), 517-549. 
Pryor, J. (2004a). What's wrong with Moore's argument? Philosophical Issues, 14(1), 349-378.

Pryor, J. (2004b). There Is Immediate Justification. in Steup, M. \& Sosa, E. (eds.), Contemporary Debates In Epistemology, Oxford: Blackwell

Pylyshyn, Z. (1999). Is vision continuous with cognition? The case for cognitive impenetrability of visual perception? Behavioral and Brain Sciences, 22, 341-423.

Roeser, S. (2011). Moral Emotions and Intuitions. Palgrave Macmillan

Senor, T. (2007). Preserving Preservationism: A reply to Lackey. Philosophy and Phenomenological Research 74 (1): 199-208.

Siegel, S. (2006). Which Properties Are Represented In Perception? in Gendler and Hawthorne (eds.), Perceptual Experience, Oxford University Press

Siegel, S. (2007). How Can We Discover the Contents of Experience? Southern Journal of Philosophy 45 (S1): 127-142

Siegel, S. (2012). Cognitive penetrability and perceptual justification. Nous, 46(2), 201-222.

Siegel, S. (2013). The epistemic impact of the etiology of experience. Philosophical Studies, 162(3), 697-722.

Silins, N. (forthcoming). The Significance of High Level Content. Philosophical Studies.

Stokes, D. (2012). Perceiving and desiring: A new look at the cognitive penetrability of experience. Philosophical Studies, 158(3), 477-492.

Stokes, D. (forthcoming). Cognitive penetrability. Philosophy Compass.

Sturgeon, N. (2002). Ethical Intuitionism and Ethical Naturalism. In P. StrattonLake (ed.) Ethical Intuitionism: Re-Evaluations, OUP

Tappolet, C. (2012). Emotions, perceptions, and emotional illusions. In C. Calabi (Ed.), In Calabi Clotilde (ed.), Perceptual Illusions. Philosophical and Psychological Essays, Palgrave-Macmillan.

Vance, J., (forthcoming). Emotion and the New Epistemic Challenge From Cognitive Penetrability. Philosophical Studies.

Vayrynen, P. (2008) Some good and bad news for ethical intuitionism. The Philosophical Quarterly, 58(232), 489-511.

Witzel, C., Valkova, H., Hansen, T., Gegenfurtner, K (2011). Object knowledge modulates colour appearance. i-Perception 2: 13-49. 